\title{
Breast fibroadenomas in adolescents: current perspectives
}

\author{
Michelle Lee \\ Hooman T Soltanian \\ Department of Plastic and \\ Reconstructive Surgery, University \\ Hospitals Case Medical Center, \\ Case Western Reserve University, \\ Cleveland, OH, USA
}

\author{
This article was published in the following Dove Press journal: \\ Adolescent Health, Medicine and Therapeutics \\ 23 September 2015 \\ Number of times this article has been viewed
}

\begin{abstract}
Fibroadenomas are one of the most common benign tumors of the breast in the adolescent population. They account for $68 \%$ of all breast masses and $44 \%-94 \%$ of all biopsied breast lesions. Fibroadenomas can range from asymptomatic masses to painful and rapidly growing tumors that can cause significant esthetic distortions of the breast. Given the prevalence of fibroadenomas in the adolescent population and the psychosocial morbidity of finding a mass in the adolescent breast, it is imperative for physicians treating adolescent patients to be familiar and up to date with this disease process. The goal of this article is to provide a brief review of the classification, etiology, symptoms, initial work-up, and update on the management of breast fibroadenomas in the adolescent population.
\end{abstract}

Keywords: breast mass, benign breast neoplasm, breast growth, breast development, breast asymmetry

\section{Introduction}

Fibroadenomas are one of the most common benign tumors of the breast in women under 30 years of age. In the adolescent population, the overall incidence of fibroadenoma is $2.2 \% .^{1}$ They account for $68 \%$ of all breast masses and $44 \%-94 \%$ of biopsied breast lesions. ${ }^{2,3}$ Histologically, fibroadenoma is a benign biphasic tumor with epithelial and stromal components. Furthermore, a palpable mass in the adolescent breast incurs anxiety for both the patient and family. The goal of this article is to provide an update on the management of breast fibroadenomas in the adolescent population.

\section{Classification}

Subcategories of fibroadenomas include simple fibroadenoma, giant juvenile fibroadenoma, and multicentric fibroadenoma. ${ }^{4}$ Seventy to ninety percent of fibroadenomas are simple fibroadenomas, the most common type of fibroadenoma. Giant juvenile fibroadenomas are a rare variant of fibroadenoma. They are defined as any rapidly enlarging encapsulated fibroadenoma with a diameter greater than $5 \mathrm{~cm}$, weighing over $500 \mathrm{~g}$, or displacing at least four fifths of the breast. ${ }^{5}$ Giant fibroadenomas are associated with skin ulcerations and venous engorgement. ${ }^{6}$ The incidence of giant fibroadenomas is approximately $0.5 \%-2 \%$ of all fibroadenomas. ${ }^{7}$ Populations susceptible to giant fibroadenomas are women aged 10-18 years old and African-American women. Giant fibroadenoma is the most common cause of unilateral macromastia in adolescent women. Multicentric fibroadenomas are multiple fibroadenomas occurring in different quadrants of the breast. The incidence of multicentric fibroadenoma is approximately $10 \%-25 \%$ of all fibroadenomas. ${ }^{4}$ Although fibroadenomas are benign
Correspondence: Hooman T Soltanian Department of Plastic Surgery, I I 100 Euclid Ave, Cleveland, OH 44I06, USA Email hooman.soltanian@uhhospitals.org (c) (i) (5) 2015 Lee and Soltanian. This work is published by Dove Medical Press Limited, and licensed under Creative Commons Attribution - Non Commercial (unported, v3.0) permission from Dove Medical Press Limited, provided the work is properly at htrbiti//creativecommons.org/licenses/lby-nc/3.0/. Non-commercial uses of the work are permitted without any further permission from Dove Medical Press Limited, provided the work is properly attributed. Permissions beyond the scope of the License are administered by Dove Medical Press Limited. Intormation on
how to request permission may be found at: http://www.dovepress.com/permissions.php 
breast masses, women with fibroadenomas are at a 2.17 times increased risk for breast cancer. ${ }^{8}$ The incidence of malignancy arising from a fibroadenoma specimen is rare, and ranges from $0.002 \%$ to $0.125 \%{ }^{9}$

\section{Causes and symptoms of breast fibroadenomas in adolescents}

More than $70 \%$ of fibroadenomas present as a single mass, and $10 \%-25 \%$ of fibroadenomas present as multiple masses. ${ }^{4}$ Typically, fibroadenoma presents as a painless, smooth, mobile, rubbery mass with distinct borders usually ranging from $1 \mathrm{~cm}$ to $3 \mathrm{~cm}$ in size on the upper outer quadrant of the breast. It can also be small enough that it is only seen on microscopic examination or it can be larger than $10 \mathrm{~cm}$ and cause breast asymmetry and significant esthetic deformation of the breast. The size of the fibroadenoma can shrink or expand spontaneously, or it can be hormonally responsive and vary in size in conjunction with the menstrual cycle. ${ }^{6}$ Fibroadenomas can also vary in clinical presentation, ranging from being asymptomatic to causing debilitating pain.

The exact etiology of fibroadenoma is unknown. However, several studies show that estrogen influences the development of fibroadenomas. ${ }^{10,11}$ In a large population study of 265,402 women, risk factors for development of fibroadenoma include young age ( $<35$ years old), self-breast examination, and prior history of benign breast disease. Exposure to an estrogen-progesterone oral contraceptive before menopause and increasing number of live births decreases the risk of fibroadenoma. ${ }^{12}$ There is also a correlation between body mass index and incidence of fibroadenoma. In a study of 1,717 patients, the incidence of fibroadenoma peaked in the body mass index group of $25-29.9 \mathrm{~kg} / \mathrm{m}^{2} .{ }^{13}$ Fibroadenomas can also be associated with syndromes such as Beckwith-Wiedemann syndrome, Maffucci syndrome, and Cowden syndrome. ${ }^{14}$

The natural history of fibroadenoma varies from individual to individual. Some fibroadenomas may remain dormant without any change in size. Others may grow slowly in size. Overall, most fibroadenomas decrease in size as they lose cellularity, infarct with resultant calcification and hyalinization. In the adolescent population, $10 \%-40 \%$ of fibroadenomas spontaneously regress.

\section{History and physical examination}

Adolescents presenting with a breast mass should undergo a careful and thorough history and physical examination. The physician should be sensitive to the fact that any breast mass in this patient population will cause significant anxiety to the patient. Clear communication and reassurance is critical. A thorough gynecologic history should be obtained. History should include age of at onset of menstrual cycle, pregnancy history, when the breast mass was first noted, changes in the size and texture of the mass, association with the menstrual cycle, associated pain, breast skin changes, and nipple discharge. The physician should also enquire about a history of prior breast mass, radiation, or malignancy, and family history of breast or ovarian cancer.

Physical examination should include a detailed breast examination and palpation of the axillary lymph nodes. For palpable masses, the size and location of the mass should be documented and monitored. Any associated skin and nipple discharge are noted. All fibroadenomas should be observed over at least one complete menstrual cycle. Imaging options include mammography, ultrasound, and magnetic resonance imaging. However, in the adolescent population, ultrasound is the best option due to the density of the adolescent breast. ${ }^{15}$ Although benign, giant juvenile fibroadenomas have characteristics similar to those of malignancy, such as distortion of breast architecture, skin changes, nipple inversion, and superficial vein dilation, so histologic analysis of the tissue should be done for giant juvenile fibroadenomas to rule out malignancy. Differential diagnosis for a breast mass in the adolescent population should include inflammatory changes, lipomas, hamartomas, breast cysts, benign juvenile breast hypertrophy, and malignancy.

Management of fibroadenomas varies from observation to open surgical excision. The risk of malignancy in fibroadenomas is less than $0.3 \%$ and exceedingly rare in women before the age of 40 years. Any intervention even as small as a biopsy may cause iatrogenic injury to the developing breast bud and result in esthetic deformity of the breast. ${ }^{16}$ The risks of intervention should not be taken lightly, and it is critical to differentiate when to intervene versus when to observe.

\section{Observation}

Fibroadenomas that are asymptomatic, not rapidly enlarging, and do not cause cosmetic deformity may be managed conservatively with yearly breast examination and ultrasound if necessary. The physician should reassure the patient about the safety of observing the fibroadenoma and that $10 \%-40 \%$ of fibroadenomas regress spontaneously. However, if the patient does not feel comfortable with observation, and fear of malignancy is causing significant anxiety despite knowing that the risk of malignancy is less than $1 \%$, asymptomatic fibroadenoma should be removed.

Intervention is warranted for fibroadenomas that are greater than $5 \mathrm{~cm}$ in diameter; increasing in size; causing 
considerable pain, distortion of the breast parenchyma, and cosmetic deformity of the breast, where there are multiple and bilateral breast masses, and where there is a persistent mass without any regression, stromal hypercellularity on ultrasound, symptoms worrisome for malignancy, presence of a high risk genetic mutation or syndrome, or a histologically complex fibroadenoma. ${ }^{17}$ When the fibroadenoma is small, if removal is requested by the patient or family, it is advisable to observe for at least 3-4 months before intervention. ${ }^{18}$

\section{Minimally invasive techniques Vacuum-assisted percutaneous biopsy}

Vacuum-assisted percutaneous excisional biopsy can be used to remove fibroadenomas up to $3 \mathrm{~cm}$ in size. The procedure involves multiple percutaneous passes of a hollow bore needle under ultrasound or stereotactic guidance. The breast tissue is then subsequently aspirated via vacuum suction. Judging by radiographic guidance, the procedure is complete when the breast mass appears to be radiographically completely removed. Wang et al demonstrated a recurrence rate of $3.4 \%$ seen on ultrasound at 6 months post procedure. ${ }^{19}$ Tumors greater than $2 \mathrm{~cm}$ were associated with incomplete removal. The most common complication is hemorrhage and hematoma, occurring at a rate of $0 \%-13 \% .{ }^{20}$ Vacuum-assisted percutaneous excisional biopsy does not provide surgical margins since the tumor is removed piecemeal through core biopsies. Despite the risk of recurrence, patients report high satisfaction with the procedure. In a survey of 134 patients, $94 \%$ of respondents reported that they would recommend this procedure to others and preferred the procedure to surgical excision. ${ }^{21}$

\section{Ablative procedures}

Breast fibroadenomas can also be removed by ablative procedures such as cryotherapy. This is generally performed in the office under local anesthesia. Cryotherapy involves percutaneous placement of a probe along the long axis of the fibroadenoma under ultrasound guidance. The probe is then subsequently cooled by argon gas to $-160^{\circ} \mathrm{C}$. The low temperature disrupts cell membranes, causes thrombosis of capillaries and hypoxia, and eventual destruction of the target fibroadenoma. The body then gradually reabsorbs the ablated fibroadenoma tissue. In situ destruction of the fibroadenoma reduces the risk of distortion of breast tissue and poor cosmesis. Furthermore, cryotherapy therapy results in minimal change to breast tissue on subsequent mammography. ${ }^{22}$ Nurko et al evaluated 444 fibroadenomas post ablation with cryotherapy. At 1-year post procedure,
$65 \%$ of fibroadenomas were no longer palpable and patient satisfaction was $88 \%$ at 1 year. Fibroadenomas less than $2 \mathrm{~cm}$ in size was associated with better outcomes in terms of resorption and nonpalpability. ${ }^{23}$ Kaufman et al evaluated 37 fibroadenomas treated with cryotherapy with an average follow-up of 2.6 years. A median volume reduction of $99 \%$ was observed by ultrasound. Overall, 16\% of the fibroadenomas remained palpable by the patient. For fibroadenomas less than $2 \mathrm{~cm}$ in size, $6 \%$ remained palpable. In this study cohort, patient satisfaction was $97 \% .{ }^{24}$ In a prospective, multicenter trial, cryoablation under ultrasound guidance, local anesthesia, and liquid nitrogen was evaluated. All fibroadenomas had a maximum diameter of $3 \mathrm{~cm}$. Of the 60 fibroadenomas evaluated, 93\% were nonpalpable and patient satisfaction with the cosmetic result was $97 \%$ at 1-year follow-up. ${ }^{25}$

Similar to cryotherapy, fibroadenomas can also be removed with heat. Dowlatshahi et al reported placing a stereotactically guided laser needle within the fibroadenoma and use of a laser to generate heat, causing ablation of the tumor and a rim of normal breast tissue approximately $2.5-3.0 \mathrm{~cm}$ in size. At 6 years and 8 years of follow-up, both their patients showed resolution of symptoms. ${ }^{26}$ Another heatbased ablative technique is high intensity focused ultrasound. In a multicenter study of 42 women with 51 fibroadenomas treated by high intensity focused ultrasound with 12 months' follow-up, the mean volume reduction of the fibroadenoma was $72.5 \%$. Side effects of ablative procedures include superficial skin burns, hyperpigmentation over the treatment area, skin indurations, recurrence, incomplete removal, and inability to obtain clear surgical margins. ${ }^{27}$

\section{Surgical excision}

Each year, approximately 500,000 fibroadenomas are treated by surgical excision. ${ }^{20}$ It is also the treatment of choice for giant fibroadenomas that cause significant breast tissue distortion. The goal of surgical excision is to completely enucleate the fibroadenoma with a rim of normal breast tissue and without causing iatrogenic deformity to the breast. Invariably, surgical excision of large or multiple fibroadenomas or giant fibroadenomas can cause deformity of the breast, which would ultimately require reconstruction. Preoperative counseling regarding potential reconstruction of the breast and scars on the breast must be undertaken with the patient and family. Furthermore, any iatrogenic damage to the breast bud may hinder breast development and eventually cause breast asymmetry. Fibroadenomas can be removed endoscopically without scars on the breast. Kitamura et al 



Figure I A I0-year-old girl with a giant fibroadenoma of the left breast.

Note: Photographs are shown preoperatively $(\mathbf{A})$ and I year post fibroadenoma excision and dermoglandular breast reconstruction $(\mathbf{B})$.

first described endoscopic removal of benign breast masses in 2001 in their study of 36 patients. The technique uses three small incisions placed in the mid axillary line, and the fibroadenoma is dissected from the surrounding tissue and removed through an Endocatch bag. ${ }^{28}$

Open excision of fibroadenomas is still the most utilized technique for excision of fibroadenomas. It can be done under local or general anesthesia. If possible, direct scars on the breast should be avoided. Incisions should be placed in esthetically hidden areas such as the circumareolar region or the inframammary crease. The need for reconstruction post fibroadenoma depends on the size of the defect after enucleation of the mass. ${ }^{29}$ Small defects that do not distort the breast architecture do not require reconstruction. Patients with secondary asymmetry should be counseled for reconstruction. Reconstructive surgery is usually delayed until at least 1 year post excision or until the patient has reached skeletal maturity. There is a possibility that the developing breast parenchyma may expand to fill in the resulting defect and resolve any residual deformity. ${ }^{2}$ However, if the fibroadenoma distorts the breast parenchyma and the skin envelope significantly, skin retraction is unlikely post excision, and the resultant deformity of the breast may cause significant distress to the patient. Breast envelope reshaping techniques, such as mastopexy and reduction, should be employed at the time of initial excision of the fibroadenoma.

Various authors have reported using the techniques such as breast reduction, adjusting the excess breast skin envelope, breast implant insertion, and free nipple grafting in the management of the adolescent breast with good success. ${ }^{3,29}$ It is important to note that aggressive breast reshaping may increase the risk of a superiorly displaced nipple-areolar complex, so the nipple-areolar complex of the affected breast should be placed $1-1.5 \mathrm{~cm}$ inferior to the nipple-areolar complex of the unaffected side and the nipple to inframammary fold distance should be less than $4 \mathrm{~cm} .{ }^{29}$ Our group has shown that early utilization of breast dermoglandular preserving reconstruction following giant fibroadenoma excision provides an excellent esthetic outcome in the adolescent population (Figure 1).

\section{Conclusion}

Fibroadenomas are one of the most common benign breast masses encountered in the adolescent population. Any breast mass can evoke anxiety in the patient. This is especially true in the adolescent population. It is critical to clearly communicate and reassure the patient throughout treatment of the natural history and benign nature of fibroadenomas, and weigh the risks versus benefits of intervention. For those masses that warrant treatment, small fibroadenomas less than $3 \mathrm{~cm}$ in diameter can be treated with minimally invasive methods. Larger fibroadenomas can be removed endoscopically or by open surgery. There is no recommendation to date on the timing of reconstruction in the adolescent breast post fibroadenoma excision.

\section{Disclosure}

The authors report no conflicts of interest in this work.

\section{References}

1. Santen RJ, Mansel R. Benign breast disorders. N Engl J Med. 2005; 353(3):275-285.

2. Cerrato F, Labow BI. Diagnosis and management of fibroadenomas in the adolescent breast. Semin Plast Surg. 2013;27(1):23-25.

3. Chang DS, McGrath MH. Management of benign tumors of the adolescent breast. Plast Reconstr Surg. 2007;120(1):13e-19e.

4. Williamson ME, Lyons K, Hughes LE. Multiple fibroadenomas of the breast: a problem of uncertain incidence and management. Ann R Coll Surg Engl. 1993;75(3):161-163.

5. Gobbi D, Dall'Igna P,Alaggio R, Nitti D, Cecchetto G. Giant fibroadenoma of the breast in adolescents: report of 2 cases. J Pediatr Surg. 2009;44(2): e39-e41.

6. Greenberg R, Skornick Y, Kaplan O. Management of breast fibroadenomas. J Gen Intern Med. 1998;13(9):640-645. 
7. Song BS, Kim EK, Seol H, et al. Giant juvenile fibroadenoma of the breast: a case report and brief literature review. Ann Pediatr Endocrinol Metab. 2014;19(1):45-48.

8. Dupont WD, Page DL, Parl FF, et al. Long-term risk of breast cancer in women with fibroadenoma. $N$ Engl J Med. 1994;331(1):10-15.

9. Wu YT, Chen ST, Chen CJ, et al. Breast cancer arising within fibroadenoma: collective analysis of case reports in the literature and hints on treatment policy. World J Surg Oncol. 2014;12(1):335.

10. Trapido EJ, Brinton LA, Schairer C, Hoover R. Estrogen replacement therapy and benign breast disease. J Natl Cancer Inst. 1984;73(5): 1101-1105.

11. Sitruk-Ware R, Thalabard JC, Benotmane A, Mauvais-Jarvis P. Risk factors for breast fibroadenoma in young women. Contraception. 1989;40(3):251-268

12. Coriaty Nelson Z, Ray RM, Gao DL, Thomas DB. Risk factors for fibroadenoma in a cohort of female textile workers in Shanghai, China. Am J Epidemiol. 2002;156(7):599-605.

13. O’Brien S, Kowdley GC. Benign breast diseases and body mass index: is there a correlation? Am Surg. 2014;80(5):461-465.

14. Poh MM, Ballard TN, Wendel JJ. Beckwith-Wiedemann syndrome and juvenile fibroadenoma: a case report. Ann Plast Surg. 2010;64(6): 803-806.

15. Garcia CJ, Espinoza A, Dinamarca V, et al. Breast US in children and adolescents. Radiographics. 2000;20(6):1605-1612.

16. Neinstein LS, Atkinson J, Diament M. Prevalence and longitudinal study of breast masses in adolescents. J Adolesc Health. 1993;14(4):277-281.

17. Jayasinghe Y, Simmons PS. Fibroadenomas in adolescence. Curr Opin Obstet Gynecol. 2009;21(5):402-406.

18. Ozzello L, Gump FE. The management of patients with carcinomas in fibroadenomatous tumors of the breast. Surg Gynecol Obstet. 1985; 160(2):99-104.

19. Wang WJ, Wang Q, Cai QP, Zhang JQ. Ultrasonographically guided vacuum-assisted excision for multiple breast masses: non-randomized comparison with conventional open excision. J Surg Oncol. 2009; 100(8):675-680.
20. Lakoma A, Kim ES. Minimally invasive surgical management of benign breast lesions. Gland Surg. 2014;3(2):142-148.

21. Thurley P, Evans A, Hamilton L, James J, Wilson R. Patient satisfaction and efficacy of vacuum-assisted excision biopsy of fibroadenomas. Clin Radiol. 2009;64(4):381-385.

22. Littrup PJ, Freeman-Gibb L, Andea A, et al. Cryotherapy for breast fibroadenomas. Radiology. 2005;234(1):63-72.

23. Nurko J, Mabry CD, Whitworth $\mathrm{P}$, et al. Interim results from the FibroAdenoma Cryoablation Treatment Registry. Am J Surg. 2005; 190(4):647-651.

24. Kaufman CS, Littrup PJ, Freeman-Gibb LA, et al. Office-based cryoablation of breast fibroadenomas with long-term follow-up. Breast $J$. 2005;11(5):344-350.

25. Golatta M, Harcos A, Pavlista D, et al. Ultrasound-guided cryoablation of breast fibroadenoma: a pilot trial. Arch Gynecol Obstet. 2015;291(6): $1355-1360$.

26. Dowlatshahi K, Wadhwani S, Alvarado R, Valadez C, Dieschbourg J. Interstitial laser therapy of breast fibroadenomas with 6 and 8 year follow-up. Breast J. 2010;16(1):73-76.

27. Kovatcheva R, Guglielmina JN, Abehsera M, Boulanger L, Laurent N, Poncelet E. Ultrasound-guided high-intensity focused ultrasound treatment of breast fibroadenoma-a multicenter experience. J Ther Ultrasound. 2015;3(1):1.

28. Kitamura K, Inoue H, Ishida M, Kinoshita J, Hashizume M, Sugimachi K. Endoscopic extirpation of benign breast tumors using an extramammary approach. Am J Surg. 2001;181(3):211-214.

29. Chepla KJ, Armijo BS, Ponsky TA, Soltanian HT. Benefits of immediate dermoglandular preserving reconstruction following giant fibroadenoma excision in two patients. J Plast Reconstr Aesthet Surg. 2011;64(9):e244-e247.
Adolescent Health, Medicine and Therapeutics

\section{Publish your work in this journal}

Adolescent Health, Medicine and Therapeutics is an international, peer-reviewed, open access journal focusing on health, pathology, and treatment issues specific to the adolescent age group. All aspects of health maintenance, preventative measures and disease treatmen interventions are addressed within the journal and practitioners from

\section{Dovepress}

all disciplines are invited to submit their work as well as healthcare researchers and patient support groups.. The manuscript management system is completely online and includes a very quick and fair peerreview system. Visit http://www.dovepress.com/testimonials.php to read real quotes from published authors. 